\title{
USO DO KIT ESCOLAR COMO EFETIVIDADE NA PRÁTICA AMBIENTAL DESENVOLVIDA COM OS ALUNOS DA ESCOLA DÓRIS MENDES TRINDADE - AQUIDAUANA/MS
}

\section{USE OF SCHOOL KIT AS EFFECTIVENESS IN ENVIRONMENTAL PRACTICE DEVELOPED WITH DORIS MENDES TRINDADE SCHOOL STUDENTS - AQUIDAUANA / MS}

Minéia Martins Cristaldo ${ }^{1}$

Elisangela Castedo Maria Nascimento²

\section{RESUMO}

A questão ambiental ganha notoriedade pela importância vital que se tem para a vida, dessa forma as escolas ficaram incumbidas de ensiná-la desenvolvendo ideias, petrificando conceitos, para então a prática se tornar diária. Este artigo tem como objetivo analisar os efeitos da educação ambiental na prática dos alunos, seu entendimento sobre meio ambiente, e as possíveis mudanças de comportamento em relação ao consumo desnecessário ou supérfluo. Para isso foi aplicado questionário aos alunos do $3^{\circ}$ ano do ensino médio da Escola Estadual professora Dóris Mendes Trindade - Aquidauana/MS, para verificar a finalidade que dão ao material escolar que ganham do governo. Verificou-se que as mudanças de comportamento mesmo que ainda tímidas já são reais, porém a visão do que é meio ambiente ainda é ingênua.

Palavras-Chave: Educação ambiental. Consumo. Teoria e prática.

\section{ABSTRACT}

The environmental issue is notorious for the vital importance it has for life, so schools were instructed to teach it by developing ideas, petrificing concepts, and then practicing daily. This article aims to analyze the effects of environmental education on students' practice, their understanding of the environment, and possible behavioral changes in relation to unnecessary consumption. For this purpose, a questionnaire was applied to the students of the 3rd year of high school at the State School, teacher Doris Mendes Trindade - Aquidauana/MS, to verify the purpose they give to the school material they earn from the government. It was verified that the changes of behavior even if still timid are already real, but the vision of what is environment is still naive.

Keywords: Environmental education, Consumption, Theory and practice.

1 Geógrafa Especialista em Educação Ambiental. Professora da Secretaria de Educação do Estado de Mato Grosso do Sul. Secretaria de Estado do Mato Grosso do Sul - SED/MS. E-mail: mineia.patricia@hotmail.com

2 Mestre em ensino de ciências. Professora da Universidade Federal do Mato Grosso do Sul (UFMS). E-mail: ecmcursino@yahoo.com.br 
AMBIENTE \& EDUCAÇÃO

ISSN - 1413-8638

E-ISSN - 2238-5533

v. 24, n.2, 2019

\section{INTRODUÇÃO}

Em função de tantos problemas ambientais, o Meio Ambiente, ganha grande destaque e passa a fazer parte da grade curricular das escolas como tema transversal. Sua obrigatoriedade é efetivada pela Lei n 9795/99 (Política Nacional de Educação Ambiental) se estendendo para todos os níveis de ensino.

Não foi criada uma disciplina que trate tal assunto, e sim uma abordagem feita por todos independente da sua área de atuação como componente urgente, contínuo e permanente no processo educativo, onde 0 Projeto Político Pedagógico (PPP) da escola auxilia nesse processo, uma vez que ele direciona as ações e metas para que se alcancem os objetivos.

Legalmente a educação ambiental está bem alicerçada, é no campo das ideias que se inicia todo o processo que culmina numa mudança de comportamento, que é o objetivo de toda teoria. Muito se ouve sobre a questão do cuidado com o meio ambiente, não só nas escolas como foi pautada grandemente pela mídia principalmente depois da crise hídrica que foi pontuada com propagandas e notícias em jornais e revistas no ano de 2015. Provocou além de muita polêmica, mudança de comportamento, não exatamente pela vontade ou educação, mas pela necessidade, porém, o ideal não são mudanças pontuais por um evento sazonal, isso torna-se fraco e temporal, é preciso que se tornem hábito.

Desta forma, procura-se com esta pesquisa, investigar os alunos do terceiro ano do ensino médio, da escola da rede estadual de ensino Professora Dóris Mendes Trindade, com o objetivo de analisar os efeitos da educação ambiental no cotidiano dos alunos, coletando informações sobre o que entendem por educação ambiental e se tudo o que estudaram em sala contribuiu para alguma mudança de hábito, confrontando o que dizem com 0 que acontece na realidade, através de investigação do uso ou não do material escolar que é dado pelo governo. O kit é distribuído para as 365 instituições do estado, para todas as séries contendo materiais conforme as necessidades de cada etapa do ensino, custando milhões aos cofres públicos sem falar no quanto isso representa ao meio ambiente em termos de utilização de matérias primas, agressão devido a produtividade e descarte dessa produção. 


\title{
EDUCAÇÃO AMBIENTAL E O CONSUMO
}

Segundo a Constituição Federal em seu Art. 225 "Todos têm direito ao meio ambiente ecologicamente equilibrado, bem de uso comum do povo e essencial à sadia qualidade de vida, impondo-se ao poder público e à coletividade o dever de defendê-lo e preservá-lo para as presentes e futuras gerações". É importante frisar que é um direito e obrigação de todos cuidar o meio ambiente, não sendo responsabilidade de apenas alguns.

Mais do que um direito e dever garantido, passa-se a disseminar sua ideologia através do ensino, colocando a educação ambiental como parte da rotina escolar, não como matéria específica e sim trabalhada em todas as áreas.

Costa (2011, p.62) defende que:

[...] Educação Ambiental, é um tema que deve ser obrigatoriamente abordado nas escolas, é interdisciplinar, podendo perpassar em todas as disciplinas, pois 0 aprendizado está fundamentado na interdisciplinaridade, todas as matérias podem ser desenvolvidas na Educação Ambiental.

Nesse sentido, a escola conta com o Projeto Político Pedagógico (PPP) que seguem orientações contidas na Lei de Diretrizes e Bases da Educação Nacional (LDB), Lei $n^{\circ}$ 9.394, de 20 de dezembro de 1996, em seus artigos 12, 13 e 14.

Segundo Cruz (2011, p. 931)

\begin{abstract}
A inserção da Educação Ambiental no PPP da escola, utilizada como prática transformadora, no sentido de questionar a situação dos problemas ambientais no planeta terra, produzidos pelo homem dentro de uma lógica de desenvolvimento decadente, responsável pela exclusão social, aumento das desigualdades sociais. Pode ser uma grande aliada na construção de uma cidadania planetária.
\end{abstract}

No universo escolar os alunos recebem informações que geram conhecimento, ajudando a desenvolver o senso crítico, ideias que, se bem pontuadas, influenciarão nas ações futuras. Ensinar as crianças de hoje é ter colaboradores no futuro engajadas em um propósito para a coletividade, formando cidadãos comprometidos com a qualidade ambiental.

Para Watanabe, (2011, p. 30): 
[...] Mudanças tão profundas de valores passam inevitavelmente pelo processo educativo. Dessa maneira, a educação ambiental surgiu como alternativa para amenizar a crise ambiental e contribuir com a construção de uma consciência voltada a participação crítica e responsável do indivíduo e da coletividade.

Então, educar passa a ser um ponto importante e indispensável para iniciar as mudanças. Medidas simples, cotidianas fazem a diferença, é necessário que conceitos sejam plantados para o despertar de uma educação refletindo na ação que vai desde não jogar lixo no chão até o não consumo de algo desnecessário, supérfluo.

Desnecessário seria além daquilo que realmente se necessita, algo sem funcionalidade. Segundo Alphadery (1992) apud Watanabe (2011, p.26), "nós não definimos livremente nossas necessidades, nós consumimos mercadorias e signos, nós somos prisioneiros da satisfação de nossas necessidades". Defendido por ele que o consumo não é apenas uma escolha e sim aceitação de ordem social e política.

Para Watanabe, $(2011$, p.28)

A mercadoria é apresentada como símbolo de identidade que estrutura não só a relação do indivíduo com o objeto, mas também sua relação com a coletividade. Dessa maneira consumimos signos (marcas/objetos) na ilusão de satisfazermos nossas necessidades e nos sentirmos incluídos na sociedade de consumo.

A vida em sociedade acaba por exigir das pessoas um padrão, que levado superficialmente não permite ver a problemática criada, uma vez que com o aumento do consumo, aumenta-se consequentemente a produção, a utilização de matéria prima em grande escala, a poluição, o descarte e por fim um amontoado de lixo.

Uma organização internacional pela sustentabilidade a Footprint Network (GFN), parceira da rede WWF, que monitora a Pegada Ecológica, fizeram vários cálculos e descobriram que se consomem em oito meses os recursos naturais que deveriam ser utilizados em um ano. Não é uma conta difícil de entender, percebe-se que há um déficit de quanto se consome e o que o planeta pode oferecer para que haja segurança de disponibilidade futura. Percebemos que além das medidas já pontuadas de cuidado com o meio ambiente, uma mudança de atitude quanto aos padrões de consumo é necessária. 


\section{O Contexto Escolar}

A Escola Estadual Professora Dóris Mendes Trindade, está localizada na Vila Santa Terezinha no município de Aquidauana - MS, um dos maiores bairros da região. A escola oferece o ensino fundamental, médio e curso técnico em biblioteconomia e o seu PPP contempla a questão ambiental.

O assunto é estudado no segundo bimestre devido à comemoração do Dia do Meio Ambiente, no dia 05 de junho. No final do bimestre apresentam os projetos realizados sobre a temática. Dessa forma, cumprem o que está posto no PPP, porém, de forma pontual, e nem todos os professores participam da discussão do assunto.

É desenvolvido na escola o PIBID onde os acadêmicos de geografia da Universidade Federal de Mato Grosso do Sul, trabalham questões ambientais para serem apresentadas na feira de ciências, sendo o tema uma escolha dos alunos.

Durante a entrevista, a diretora adjunta, explicou que existem muitos feriados além da escola participar de várias atividades como olimpíadas de matemática, de língua portuguesa, as provas externas do governo, atividades referentes a datas importantes como aniversário da escola, feira de ciências entre outras, e que o conteúdo precisa ser cumprido, não dando tempo de trabalhar as questões ambientais com a profundidade que deveria.

\section{Kit Escolar}

Segundo o site do governo, Notícias $\mathrm{MS}^{1}$ (2015), a Secretaria de Estado (SED) distribui para as 365 instituições o Kit escolar que contempla alunos do ensino fundamental, médio, educação de jovens e adultos (EJA) e educação profissional. Os materiais correspondem à etapa de ensino dos alunos. São três kits: o kit 01- é direcionado aos estudantes do $1^{\circ}$ ao $5^{\circ}$ ano do ensino fundamental, sendo composto por: seis cadernos capa dura, um caderno de desenho, um caderno de caligrafia, quatro lápis preto, uma caixa de lápis de

http://www.noticias.ms.gov.br/governo-garante-entrega-de-330-mil-kits-escolares-no-inicio-do-anoletivo/ 
cor, duas borrachas, um apontador, uma régua, uma caixa de giz de cera, uma caneta azul e uma agenda; o kit 02- é distribuído para alunos do $6^{\circ}$ ao $9^{\circ}$ ano e EJA do ensino fundamental, contendo: três cadernos universitários, um caderno de desenho, quatro lápis preto, uma caixa de lápis de cor, duas canetas nas cores azuis e vermelhas, duas borrachas, uma régua, um transferidor, um esquadro, um apontador, uma tesoura e uma agenda; o kit 03é direcionado aos alunos do ensino médio, EJA médio e educação profissional sendo composto pelos mesmos materiais dos alunos da segunda fase do ensino fundamental.

De acordo com notícias do Campo Grande News ${ }^{2}$ (2015), jornal eletrônico, para o fornecimento do kit escolar, foi aberto um pregão para definição da empresa com a melhor proposta. A empresa vencedora foi a Brink Mobil Equipamentos Educacionais (Brasília - DF). Consta em publicação no DIÁRIO OFICIAL n. 9.040 de9 de novembro de 2015 a Superintendência de Licitação - SL/SAD/MS, em conformidade com o $\S^{\circ}$ do artigo 15 do Decreto $\mathrm{n}^{\circ}$ 11.759 de 27/12/2004, tornou público o Realinhamento de preço dos kits escolares, fixado os seguintes valores: o valor máximo do kit destinado as séries do ensino fundamental é de $R \$ 34.71$, e dos kits 2 e $3 R \$ 43,24$ por aluno. Totalizando $\mathrm{R} \$ 10.764 .425,04$ (Dez milhões setecentos sessenta e quatro mil quatrocentos e vinte e cinco reais e quatro centavos).

\section{METODOLOGIA}

Foi realizada uma pesquisa de campo de caráter exploratório, descritivo e qualitativo, na Escola Estadual Professora Dóris Mendes Trindade. Os alunos do terceiro ano do ensino médio foram os sujeitos da pesquisa, porque estão concluindo a educação básica e considera-se que já absorveram todo conhecimento que a escola poderia oferecer.

O objetivo dessa pesquisa foi verificar se o conhecimento de educação ambiental recebido na educação básica contribuiu para alguma mudança de hábito, investigando o uso do material (kit) que é dado pelo governo.

\footnotetext{
${ }^{2}$ http://www.campograndenews.com.br/cidades/empresa-nao-cede-ao-governoe-mantem-valor-de-kit-em-rs-105.
} 
Primeiramente foi realizado o levantamento prévio de dados técnicos: PPP e projetos específicos voltados para educação e sensibilização ambiental. Posteriormente foi feita a aplicação de questionário contendo 11 questões, com técnica de entrevistas semi-estruturadas. Por meio do questionário os alunos discorreram seus conhecimentos sobre educação ambiental e sobre suas práticas para minimização dos impactos ambientais e 0 consumo desnecessário.

Esse questionário foi aplicado no período matutino para a turma do $3^{\circ}$ ano $A$, e no período noturno para o $3^{\circ}$ ano $B$. No total as duas salas possuiam 73 alunos, porém, o questionário foi respondido por 58 alunos que estavam presentes. Os resultados foram tabulados e demonstrados através de gráficos.

\section{RESULTADOS E DISCUSSÃO}

A primeira questão (discursiva) pedia a definição de meio ambiente. As respostas não se divergiram, ficaram em torno da explicação que é o lugar onde se vive, plantas, animais e seres vivos. Dessa forma, percebe-se uma visão naturalista e reducionista, que separa o homem da natureza, muito difundida na mídia e que distorce o conceito de meio ambiente, enxergando a natureza como "boa, pacificada, equilibrada, estável em suas interações ecossistêmicas, o qual segue vivendo como autônomo e independente da interação com o mundo cultural humano" (CARVALHO, 2008, p. 35).

Na questão 2 de múltipla escolha foram colocadas quatro alternativas com a contribuição para minimização dos impactos ambientais e uma em aberto para que pudessem descrever livremente. Do total de alunos apenas 2 não fazem nada, 5 contribuem de duas maneiras, 15 praticam três dessas ações, 8 fazem todos os itens listados e a maioria 28 contribuem apenas de uma maneira. Não houve nenhuma reposta espontânea dos alunos de alguma ação que praticassem e não estivesse listada, mostrando assim que não possuem uma visão crítica.

Nota-se uma sensibilização dos entrevistados, levando-se em conta que apenas $3.44 \%$ dos entrevistados não contribuem de nenhuma maneira para a minimização de impactos ambientais. A grande maioria contribui jogando lixo no lixo, mas o problema é bem maior, visto que para produção de qualquer 
bem se utiliza de recursos naturais. O consumo é inevitável, gera qualidade de vida e move a economia, porém, seu exagero está comprometendo os recursos naturais dos quais não se vive sem.

Figura 01 - Total de alunos que contribuem para minimização dos impactos ambientais.

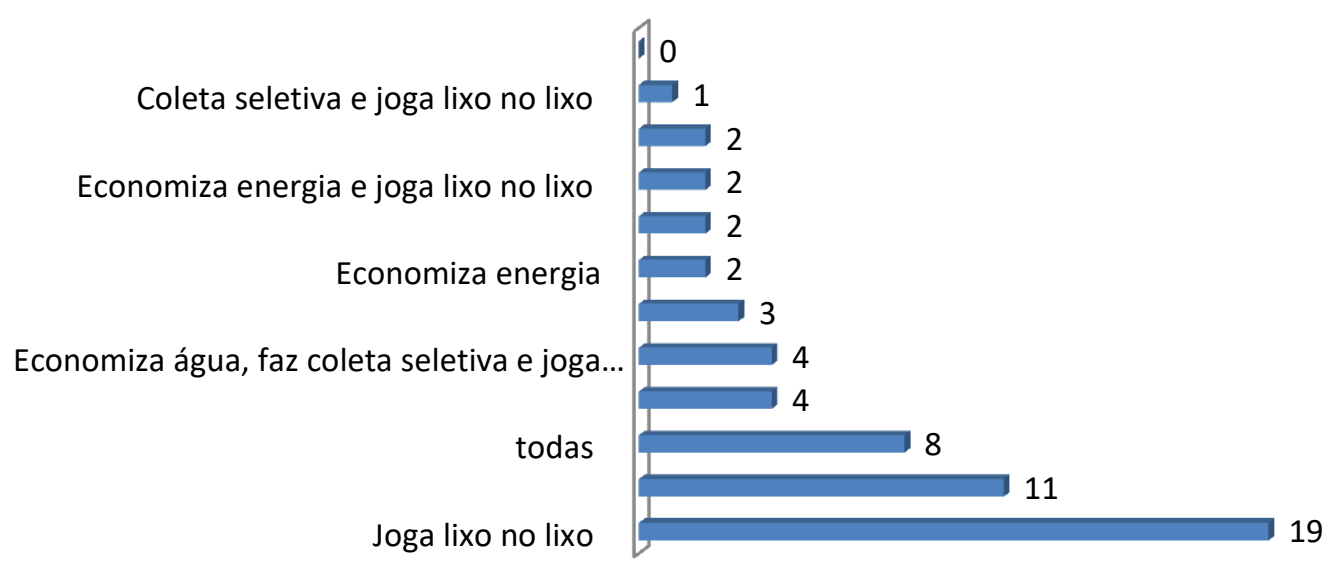

Fonte:elaboração própria

Questão três: se já haviam trocado algo que ainda estivesse bom. 30 alunos disseram que não trocaram e 28 afirmaram que sim, sendo roupas, calçados e celulares. Prevaleceram os que não trocaram como está demonstrado na figura 02.

Figura 02 - Troca de algum objeto que ainda atendia sua funcionalidade

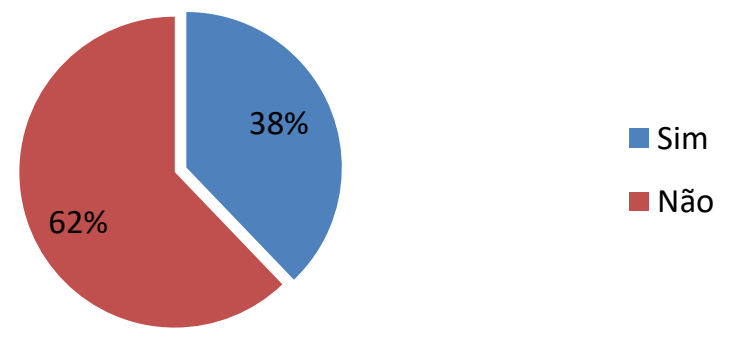

Fonte: elaboração própria

Ao justificarem os motivos que os levaram a trocar algo que ainda estava bom, as respostas foram simplesmente porque queriam ou por não gostar do que tinham. Dos 28 que disseram trocar mesmo o objeto atendendo a funcionalidade, 11 não justificaram o porquê adquiriu algo novo. 
De acordo com Vilhena (2012, s/p.)

O adolescente está na fase de construção de sua identidade e ainda não tem o aparato psíquico desenvolvido o suficiente para lidar com a avalanche de "necessidades impostas" pelo meio em que vive. Ele acredita que isso fará parte da vida e fará o possível para se encaixar nos padrões ditados por uma sociedade consumista e superficial.

Segundo o portal da educação, os adolescentes são visados por certas marcas onde "Os veículos de comunicação usam a principal característica do adolescente (se sentir aceito) para explorarem a vontade de consumo na adolescência", (Portal da educação, 2014). Isso mostra que não são as pessoas que escolhem as marcas, elas que se fazem ser escolhidas, atendendo ao anseio que elas mesmas criam.

Em relação a questão 4 destinos do objeto: 5 venderam, 14 deram, 1 jogou no lixo e 6 não sabem nem onde o objeto está e 2 não responderam, ilustrado na figura 03.

Figura 03 - Destino do objeto que trocaram.

$\begin{array}{ll}\text { Vendeu } & \text { Deu } \\ \text { não sabe onde está } & \text { Não respondeu no lixo }\end{array}$

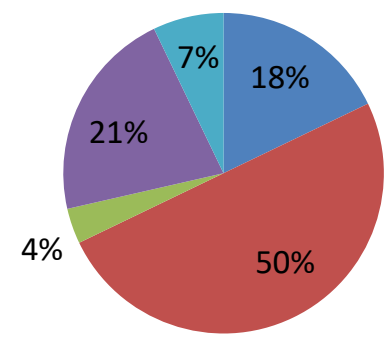

Fonte: elaboração própria

Pode-se perceber que a maioria dos objetos ainda continuaram sendo usados, mas há quem jogue mesmo o produto estando bom e aqueles que nem se preocuparam em dar um correto fim.

A questão 5: Procura saber se já mandaram consertar algo em vez de comprar um novo, a opção de arrumar coloca esse objeto novamente em uso o que contribui para a não aquisição de mais um objeto e seu descarte prematuro. Conforme respostas, a maioria já mandou arrumar algo, isso é um bom indício, pois, esse objeto vai acabar tendo serventia a outra pessoa. 
A questão seis: $O$ destino dos objetos que não mandaram arrumar, do total de 15,1 trocou, 7 pessoas deram e 7 jogaram no lixo, como mostra a figura 04.

Mandar arrumar é uma opção, porém nem sempre é vantajoso, depende do valor do produto e do conserto que se indica não ultrapassar de $35 \%$ do valor de um novo, segundo o engenheiro eletrônico Paulo Ricardo Menegotto, que desaconselha o conserto que pode não ficar confiável ou com custo alto (PIONEIRO, 2010) ${ }^{3}$. Porém, o ideal é esgotar as possibilidades para alongar seus dias úteis.

Figura 04 - Destino do objeto que não mandaram para o conserto.

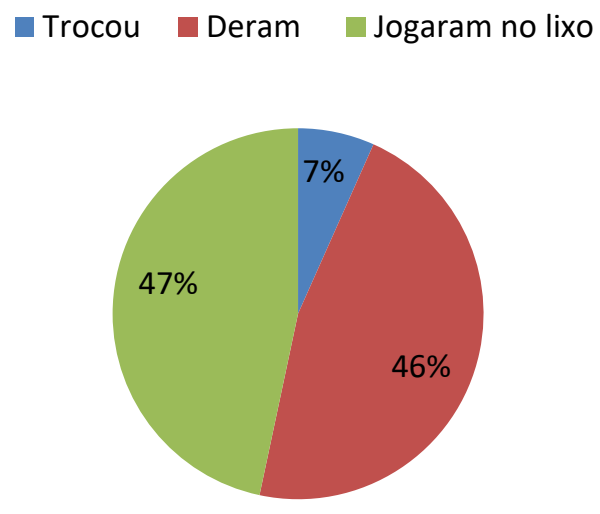

Fonte: elaboração própria

A questão sete sonda o poder de compra. Percebe-se que muitos não trocaram algo que ainda atendia sua funcionalidade, porém, ao se colocar a hipótese do poder de compra o resultado mudou isso fica evidente com 0 aumento das pessoas que responderam positivamente, 37 disseram que sim (64\%) e 21 não trocariam (36\%), figura 05.

Houve um aumento quando se propôs a hipótese do poder de compra, a ação de comprar só é efetivada quando se pode pagar, porém, nem todos possuem tal condição. De acordo com o jornal da globo (2016), o consumidor está com poder de compra menor, com encolhimento de $3.8 \%$ da economia em

\footnotetext{
${ }^{3}$ Site de notícias, disponível em http://pioneiro.clicrbs.com.br/rs/noticia/2010/11/saiba-quando-consertar-umaparelho-com-defeito-e-melhor-do-que-comprar-um-novo-3114813.html
} 
relação a 2015, sendo este o pior resultado em 25 anos, resultado do desemprego e queda da renda.

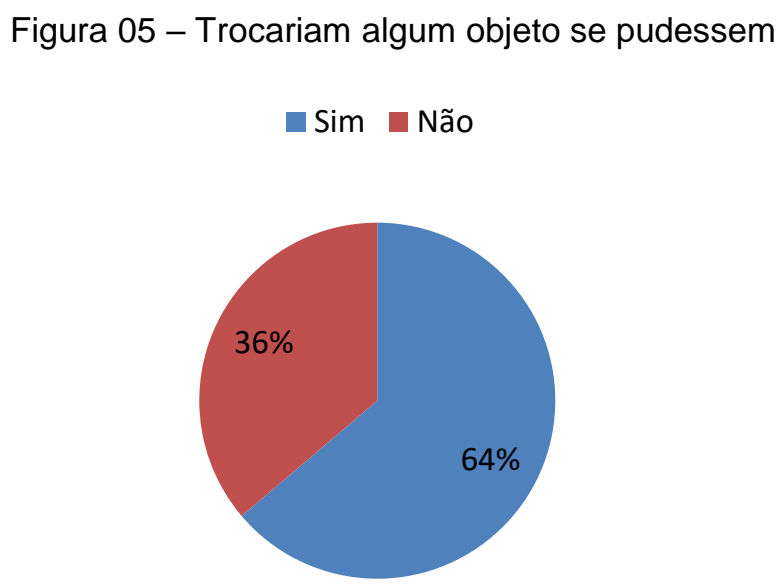

Fonte: elaboração própria

Como o consumo precede de um poder de compra ou até do discernimento da necessidade ou não, procurou-se saber com a questão oito quem é o responsável pela compra de materiais que supostamente precisam, a minoria compram seus materiais, apenas 6 pessoas, isso se deve provavelmente a faixa etária dos alunos e por talvez serem estudantes.

$\mathrm{Na}$ questão nove: investigou se os pais cedem facilmente ou pedem justificativa ao do filho sem questionar o porquê de se comprar algum material escolar, uma vez que recebem o kit. Há várias maneiras de convencer o responsável (pai ou mãe) da necessidade de se comprar algo. Pode ser pela insistência e justificativa ou então apenas avisar, isso vai depender das condições financeiras e do senso crítico da família ao julgar essa necessidade verdadeira ou não. Dos 58 alunos, 32 apenas lembram os responsáveis de que precisam comprar os materiais escolares, 15 precisam insistir e justificar, 5 não responderam e os outros 6 compram seus próprios materiais, demonstrado na figura 06.

A questão dez: Faz o levantamento da questão do uso dos materiais escolares, 25 alunos usam tudo que está no kit, sendo que 15 usam por vontade própria, 1 os pais não quiseram ou não puderam comprar, outros 09 não responderam. 33 alunos não usam todos os materiais, sendo que deste 
total, 30 não gostam da qualidade, 1 acha feio e 2 não vê necessidade no uso de alguns componentes do kit, ilustrado na figura 07.

Figura 06 - O que fazem para que seus pais comprem os materiais necessários.

Não responderam $\quad$ Apenas lembrar Insistir ou justificar

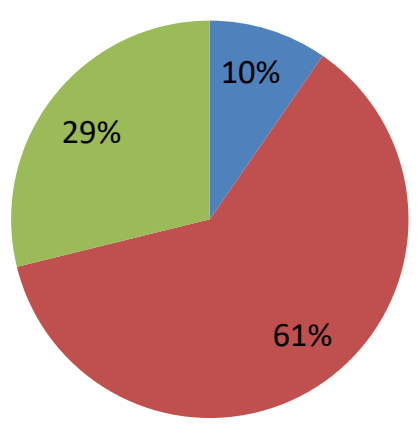

Fonte: elaboração própria

Figura 07 - Utilização dos materiais escolares que ganham do governo

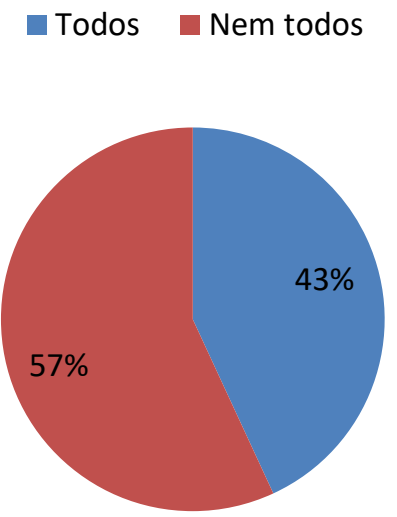

Fonte: elaboração própria

Nota-se que todos usam os materiais do kit, contribuindo assim para economia e também para o meio ambiente, afinal, evita-se o consumo desnecessário, sendo que poderia ser mais efetiva e alcançar um resultado melhor se os materiais tivessem boa qualidade, já que é o maior motivo para a substituição de alguns itens. Dentre os materiais que não agradam os alunos estão: caneta, lápis, lápis de cor, borracha e apontador, o caderno foi citado por não gostar da imagem da capa, já a régua e a agenda foram citadas como desnecessárias, como mostra a Figura 08. 
Figura 08 - Itens que não usam.

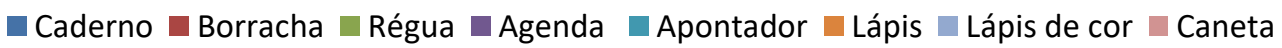

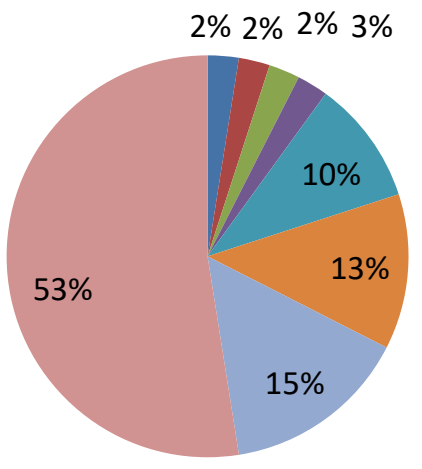

Fonte: elaboração própria

O maior percentual de reclamações foram referente às canetas, todos que a citaram alegou que elas falham ou afundam a ponta; os lápis de cor foram reprovados por não sair cor e quebrarem facilmente; os lápis de grafite também por quebrarem; os apontadores quebram a ponta do lápis; a falta de necessidade descrita foi pelo não uso da agenda e pelo pouco uso da régua, podendo portanto ser dispensada; a borracha por sujar o caderno; e o caderno não agrada pela sua capa, sendo o problema visual e não funcional.

\section{CONSIDERAÇÕES FINAIS}

Saber o que é meio ambiente leva a compreender a importância de seu equilíbrio para a vida na terra, tornando indispensável o seu cuidado. Consciência todos tem o que falta é fomentá-la, e pensando nisso que a educação ambiental ganha espaço na vida dos alunos que estão em busca de saberes e constroem a todo momento através de informações e questionamentos sua base para o futuro.

Partindo do pressuposto que as ações precedem de ideias, no campo da ideologia que elas ganham formas, percebe-se que a educação ambiental está surtindo efeito, mesmo que de forma limitada e pontual uma vez que não 
citaram nada além do que estava listado, porém, são ativos contribuindo para minimização dos impactos ambientais.

Nota-se falta de conhecimento do que é meio ambiente o que contribui para a limitação da visão do que envolve toda a problemática, não fazendo a correlação por exemplo do destino final do lixo com a coleta seletiva, a economia de energia e água com o processo agressivo de produção, nem se quer lembrando do consumo como base de toda cadeia produtiva, esgotamento de recursos naturais, perdendo nexo até do porque desse consumo.

$\mathrm{Na}$ prática, ao fazer uso dos materiais escolares, contribuem para a economia da família e também evita que outros sejam adquiridos sem necessidade, cumprindo seu papel social e ambiental, no entanto não caracteriza aqui como resultado dessa educação, tendo em vista que o não consumismo não foi citado como uma prática para minimizar os impactos ambientais possuindo o hábito de consumir desnecessariamente. $O$ que acontece é que o material escolar não é algo visado uma vez que ninguém o cita como desejo de troca. Considerando que a mídia não propaga a necessidade de se ter alguma marca específica de material, e no ambiente escolar todos recebem os mesmos itens, usá-los não os destoam, isso acaba por contribuir para sua utilização. Evidencia-se os reflexos da apelação da mídia, o quanto o planeta ganharia se não fossem vendidas ideias de consumo, onde as decisões não seriam tomadas por padrões plantados.

Entender a questão ambiental se tornou indispensável para a sobrevivência no planeta e fazer com que isso se internalize leva tempo, é necessário um trabalho contínuo para que mude a cultura de um povo que até pouco tempo nem sabia do que se tratava o tal "desenvolvimento sustentável".

É importante que se eduque que desperte esse sentimento crítico, ativo em cada um, é um trabalho novo, que requer tempo e persistência, afinal, mudar a visão de um povo tão massacrado e alienado pela grande massa formadora de opinião não é um trabalho simples, de nada adianta poder aquisitivo para comprar se o planeta não tiver o que oferecer. Do luxo teremos quem sabe o mínimo do mínimo ou então a extinção da raça humana, é preciso que desperte essa consciência que culmine em ações e não apenas use a bandeira como um discurso politicamente correto. 
Há outro problema que precisa ser revisto, não basta falar do modo de produção, do consumismo exagerado, se a cada dia que passa mais se necessita desse consumo, uma vez que muitos dos produtos produzidos não atendem a um padrão de qualidade e pedem sua substituição simplesmente por não corresponder a sua funcionalidade, compra-se o ruim que continua em produção por ter mercado e requisita mais produção para substituí-lo. O alerta tem que ser também para qualidade desses produtos que são descartados prematuramente, gerando mais resíduos. Há uma falsa ideia que se produzem produtos mais baratos para que se tornem acessíveis, quando na realidade culmina no consumo, produção em dobro.

A educação ambiental como o fundamento de toda ação precisa ser bem trabalhada, pois os resultados dependerão de como ela é difundida, não basta automatizar ações, fazer o que dizer o politicamente correto, é preciso que criem o senso de atitude, que sejam capazes de avaliar ações e não decorar quais são elas, mesmo porque, se tem a escola que pontua, tem a mídia que convence. 


\section{REFERÊNCIAS}

BARCELLOS, G. A Alma do consumo. 04 de dezembro de 2008. Disponível em: http://www.diplomatique.org.br/artigo.php?id=291. Acesso em: 14/07/2016.

BRASIL, CONSTITUIĈÃO DA REPÚBLICA FEDERATIVA DO BRASIL DE 1988. Disponível em:

http://www.planalto.gov.br/ccivil 03/constituicao/constituicaocompilado.htm. Acesso em:14/07/2016.

BRASIL, Conferência Rio-92 sobre o meio ambiente do planeta: desenvolvimento sustentável dos países. Disponível em: http://www.senado.gov.br/noticias/Jornal/emdiscussao/rio20/ario20/conferencia-rio-92-sobre-o-meio-ambiente-do-planeta-desenvolvimentosustentavel-dos-paises.aspx. Acesso em: 15/07/2016.

BRASIL, Diário Oficial n. 9.040. 9 de novembro de 2015. Disponível em: http://www.spdo.ms.gov.br/diariodoe/Index/PaginaDocumento/42242/?Pagina= 26. Acesso em: 14/07/2016.

BRASIL, Diário Oficial $\mathbf{n} . \mathbf{9 . 0 5 2}$ de $\mathbf{2 5}$ de novembro de 2015.http://www.spdo.ms.gov.br/diariodoe/Index/PaginaDocumento/42256/?Pa gina $=19$. Acesso em: 14/07/2016.

BRASIL, LEI N 9.795, DE 27 DE ABRIL DE 1999.Disponível em: http://www.mma.gov.br/port/conama/legiabre.cfm?codlegi=321. Acesso em: 14/07/2016.

BRASIL, Lei de Diretrizes e Bases da Educação Nacional (LDB) 1996. Disponível em: http://www.planalto.gov.br/ccivil 03/leis/L9394.htm Acesso em 15/07/2016.

CARVALHO, Isabel Cristina de Moura. Educação ambiental: a formação do sujeito ecológico. 3. ed. São Paulo: Cortez, 2008.

COSTA, Paulo Rodrigues. Educação ambiental no ensino médio: uma análise da prática docente em uma escola estadual de Belém-Pará / Paulo Rodrigues Costa. - 2011. Dissertação (Mestrado) -- Universidade da Amazônia, Programa de Pós-Graduação em Desenvolvimento e Meio Ambiente Urbano, 2011.

CRUZ, Silvana. Educação ambiental e o projeto político-pedagógico: em busca da sustentabilidade ambiental. Periódico Eletrônico. Fórum Ambiental da Alta Paulista. ANAP- Associação Amigos da Natureza da Alta Paulista. V. 07, N. 06, 2011.

LOUREIRO, F.; LAYARGUES, P.; CASTRO, R. (Org.) Educação ambiental: repensando o espaço da cidadania. São Paulo: Cortez, 2002, 179-220.

PORTAL DA EDUCAÇÃO. O consumo na adolescência. 15/01/2014. Disponível em: 
https://www.portaleducacao.com.br/contabilidade/artigos/53595/o-consumo-naadolescencia. Acesso em: 15/072016.

VILHENA, B. Adolescência: alvo fácil para o consumismo. Disponível em: http://dinheirama.com/blog/2013/04/23/adolescencia-alvo-facil-para-oconsumismo/. Acesso em: 14/07/2016

WATANABE, C. B. Técnico em meio ambiente. Módulo I. Fundamentos teóricos e Práticas da educação Ambiental. Geologia Ambiental. Metodologia em EAD. Curitiba - PR, 2011.

WWF. Este ano, a data chegou mais. Chegamos ao limite! 08 de agosto. Dia da sobrecarga da terra. Disponível em: cedohttp://www.wwf.org.br/natureza_brasileira/especiais/pegada_ecologica/ove rshootday/. Acesso em: 15/07/2016 